\title{
Case Study on Persuasiveness of Argument Texts Written by Proficient and Less Proficient Malaysian Undergraduates
}

\author{
SU-HIE TING ${ }^{1}$ \\ HUMAIRA RASLIE \\ LEONG-JIN JEE \\ Centre for Language Studies \\ Universiti Malaysia Sarawak \\ shting@cls.unimas.my ${ }^{I}$
}

\begin{abstract}
Purpose - Research has shown that university students, particularly non-native speakers of English, encounter difficulties with various academic text-types and often lack the ability to organise the information in a structure considered effective by the discourse community or to use the significant language features of the text-type effectively to achieve the intended purpose. The study examined the persuasiveness of argument texts written by proficient and less-proficient undergraduates in a Malaysian university. The aspects examined were the organisational structure of the text and the language features significant for fulfilling the persuasive purpose of the text.
\end{abstract}

Method - Forty argument texts were analysed: 22 written by undergraduates who were more proficient in English, and 18 by lessproficient undergraduates. The analysis focused on the organisation of the content of the argument text as well as selected language features, namely, connectors, modal verbs and passive voice.

Findings - The results showed that the proficient undergraduates used the structure considered effective for argument texts but the writing of the less-proficient group was characterised by unclear or absence of statement of stance and restatement of stance. To achieve the persuasive purpose of the text, the proficient undergraduates made use of connectors, modal verbs and passive voice more than the less-proficient group. However, the connectors 'because', 'so' and 'besides' were often used in a manner similar to spoken language, 
and there was an overdependence on the modal verbs 'can' and 'will'. The lack of conditionals and nominalisations was obvious for both groups, suggesting that these are more difficult language features to master and greater pedagogical attention is needed.

Significance- The paper explores differentiated focus in the teaching of academic writing at university level for students with high and low proficiency in English.

Keywords: Argument texts, English proficiency, academic writing, university

\section{INTRODUCTION}

Undergraduates beginning their university studies have to adjust to a higher level of academic reading and writing. The transition from reading textbooks and writing compositions to "understand[ing] complex academic discourse, especially academic research articles and books, as well as course lectures" is difficult for many undergraduates (Biber, 2006, p. 1). The difficulty lies in the subject matter and the academic language. University students need to engage with the meanings of specialised disciplines:

Reading can no longer serve as largely a process of decoding and memorisation and writing becomes much more than copying or imitating. Students are now required to construct new knowledge from and in text and critique this knowledge. (Cullip \& Carol, 2002)

To demonstrate knowledge of the subject matter, undergraduates are expected to refer to numerous sources of information, compare and critique the information. It is no longer personal opinions which count. According to Grabe and Kaplan (1996):

... advanced academic contexts seldom place great store in personal knowledge and impressionistic interpretations. Instead advanced academic contexts require information from other sources, and a main goal of advanced complex writing activities is the analysis, synthesis, and interpretation of information from a variety of sources. (p. 344) 
Undergraduates are expected to develop awareness of intertextuality, or the ability to draw from and depend on other texts and discoursal experiences in some way (Johns, 1997). The intertextuality is reflected in citations and references, a distinguishing feature of academic language. A study on the academic writing of 60 undergraduates in a Malaysian university revealed that a majority did not comply with the American Psychological Association (APA) stylistic conventions of citation and referencing in their assignments despite being taught these conventions in an English for Academic Purposes course (Ting \& Tee, 2008a). Besides having to demonstrate features of intertextuality in their academic writing, undergraduates also encounter academic writing tasks different from those given in high school.

Research on university writing tasks has indicated an inclination towards a need for higher level cognitive skills in processing information from academic texts. From the analysis of 54 actual writing assignment handouts and essay examinations given to students in a medium-sized United States university, Horowitz (1986) found seven categories of tasks (e.g. case study, annotated bibliography). These tasks emphasise reorganisation and critique of knowledge and de-emphasise invention and personal discovery. Another study indicated that academic writing courses may not be preparing university students for the expectations of discipline lecturers. Zhu's (2004) analysis of 95 course syllabi and handouts on writing assignments from undergraduate and graduate business courses in a large research university in the United States showed that the more common academic genres cast the writers essentially in their role as learners while the disciplinary genres initiated students into their professional role as business people solving realworld problems and employing business communication devices. To address the skills required in assignments, Zhu suggested the use of problem-oriented writing with an emphasis on awareness of professional audiences in English for Academic Purposes courses. Similar findings on the discrepancy between the emphasis of academic writing courses and requirements of academic writing in the disciplines were found by Jackson, Meyer and Parkinson (2006). Jackson et al. also recommended that the Science Communications courses in a South African university focus on analysis of measured data in laboratory report writing and include research articles as models of the target discourse rather than the discursive essay genre which is the focus of many generic academic literacy courses. 
The discursive essay genre can be understood more specifically as encompassing various genres. Genres are specific text-types which are "staged, goal-oriented and have particular linguistic features" (Gerot \& Wignell, 1994:17). Examples of genres include the information report (classification-type), argument, discussion, explanation and instruction. As far as genres are concerned, Cullip and Carol (2002) stated that science students are required to classify, describe and explain whereas the social science students classify, describe, argue and discuss. In this light, it can be surmised that science students at university are more likely to be given assignments requiring them to write objective and factual texts such as explanation, information report and procedural texts compared to arts students who write more discussion and argument texts. However, with a growing emphasis on interdisciplinary concerns in tertiary education, science students may also be asked to discuss and present arguments on issues related to their discipline such as bio-ethics, renewable energies and impact of technological advancements on the people.

Research findings on university students' ability to handle various genres have indicated unfamiliarity with the macroorganisational structure of genres. Jenkins and Pico (2006) compared the argumentative essays written by English majors in Argentina and students learning English to undertake postsecondary education or to re-enter a profession in Australia. A systemic functional linguistic analysis of the argumentative essays indicated that the Tucuman (Argentina) essays are 'appropriately structured; three of them following the 'West and pollution' model of 'pivot' for-and-against paragraphs, while the fourth assigns the two positions a paragraph each, using the second of these to counter the position presented in the first' (Jenkins \& Pico, 2006, p. 158). As for the Melbourne (Australia) group, Jenkins and Pico reported that the two better writers produced well organised essays, with "advantages" paragraphs preceding "disadvantages" paragraphs but the two weaker students both had difficulty with introductions and conclusions. The difficulty lies in the wording of the stance and the restatement of stance in argument texts.

For other types of academic texts such as information report and explanations, the main difficulty also lies in the staging of the text. In a study on the impact of an English for Academic Purposes course on university students' writing skills, Ting and Law (2008) found that out of the ten undergraduates who chose to write information reports at the beginning and the end of the course, only three produced the 
structure of information reports. An information report begins with a statement of classification followed by description of sub-classes, but the conclusion is optional (Derewianka, 1991). Another four students wrote unclear classification statements and inappropriate conclusions while another four deviated considerably in the structure. Besides the information report, the Malaysian university students were also found to lack ability to organise information in explanations of how and why a particular phenomenon happens. From their analysis of explanations of a molecular biology technique written by Biology university students, Ting and Tee (2009) found that about half of the 40 university students failed to clearly state the technique to be explained and to coherently explain the steps in the process. A comparison across academic text-types revealed that the staging of discussion and argument texts was easier than that of procedure, explanation and information report for undergraduates in the Teaching of English as a Second Language degree programme (Ting \& Tee, 2008b). To date, the structure of academic texts is still under-researched as the attention has been on the language features of various genres.

Studies have shown particular importance of certain language features to types of academic texts. For narrative and persuasive texts, the use of connectives to enhance coherence and unity has been studied. Millis, Graesser and Haberlandt (1993) strongly argue against a writing policy of blindly inserting connectives into a text, based on their study which showed that connectives do not help memory of expository texts, with temporal connectives having the worst effect on recall compared to causal and intentional connectives. On the contrary, Degand and Sanders (2002) found that the presence of causal relational markers help expository text comprehension in L1 and L2 when learners had high enough English proficiency. However, Zadeh's (2006) findings showed that the low English proficiency group among Iranian undergraduates benefited from the logical connectors placed in the texts, bringing them on par with the intermediate group in their comprehension. Instead of the learners' English proficiency being the main factor as found by Degand and Sanders, it was the type of text and the presence of logical connectors that influenced the reader's ability to comprehend logical relationships in Zadeh's study. Lee (2003) brought another perspective into this investigation by comparing the use of connectives by native and non-native speakers of English. Lee compared the narrative texts written by 40 Hong Kong Chinese tertiary students (in both English and Chinese) and 40 English 
speakers of similar age and educational background. Lee's findings showed that the Hong Kong Chinese university students had a high density of connectors used but lacked variety compared to native English speakers. Malaysian university students also used connectors frequently in their writing of explanation texts but relied on a few common connectors such as then, after, when and first (Ting \& Tee, 2009).

Modality is another language feature of academic texts which has been much researched. In the context of information exchange, modality covers the space between a positive and a negative message by showing how valid the information is in terms of probability or usuality and the speaker's commitment "to the validity of what s/ he is saying" (Thompson, 1997, p. 60) (cited in Jenkins \& Pico, 2006 , p. 165). Besides modality, some other language features of persuasive texts drawing researchers' attention are theme and rheme, connectivity and transitivity (Jenkins \& Pico, 2006). Modality is not only of relevance to persuasive texts but also to research articles. Guinda (2003) examined modality as a convergence strategy and embedded subjective space in her study of 50 technical research articles written by Spanish researchers and native speakers of English in aeronautical engineering and related disciplines. Guinda found that Spanish writers needed training in "the proficient handling of hedging and boosting techniques (and especially of reader-oriented hedges) in order to pre-empt pragmatic failures which every so often go unnoticed during the screening proceedings prior to publication" (p. 231). Modality is one of the language weaknesses of non-native speaker contributions, based on Flowerdew's (2001) interviews with editors of applied linguistics journals.

Studies have shown that the passive voice has been underused in academic texts by non-native speaker students. Hinkel's (2004) analysis of academic essays written by 746 speakers of seven languages (English, Chinese, Japanease, Korean, Indonesian, Vietnamese \& Arabic) in four US universities demonstrates that even after many years of L2 learning and use, advanced non-native speaker students may have difficulty with the conventionalised uses of tenses, aspects and the passive voice in written academic discourse. Hinkel (1997) found that the passive voice, among others, was used in greater frequencies by the non-native speaker students than the native speaker students as an indirectness device and marker.

Thus far, research in the field of academic writing has indicated that university students experience difficulties in structuring various 
types of academic texts (Ting \& Tee, 2008a; 2008b), particularly explanation texts (Ting \& Law, 2008; Ting \& Tee, 2009). In the aspect of language features of narratives and persuasive texts, studies have shown that non-native speakers of English are weak in the use of modality (e.g. Flowerdew, 2001; Guinda, 2003) and connectors (e.g. Lee, 2003; Ting \& Tee, 2009). However, there is a need for studies on academic texts which integrate attention to the text structure and significant language features of the genre as both are important to achieve the purpose of the text (see Derewianka, 1991; Feez, 1998). In the making of meaning, Derewianka stresses how language operates at the text level, not at the level of individual words and sentences in isolation. The importance of structure cannot be underestimated as "the reason students' writing often goes wrong is not because of surface errors such as spelling or the inappropriate choice of vocabulary, but because they are not abiding by the conventions of the genre in some way" (Sidaway, 2006, p. 24). Studies that examine both the text structure and the language features would shed light on aspects which are relatively easy for non-native speakers of English to master and aspects which are difficult even for those who are proficient in English so that the teaching of academic writing can be tailored to the proficiency level of university students.

\section{PURPOSE OF STUDY}

The study examined argument texts written by students of high and low English proficiency at a Malaysian university. The specific aspects examined were the structure of the argument text and the language features significant for fulfilling the persuasive purpose of the text. By using text analysis of persuasive texts produced by university students, this study seeks to uncover the strengths and the weaknesses of university-level academic writing to provide evidence-based pedagogical applications for the development of an effective academic reading and writing curriculum.

\section{THEORETICAL FRAMEWORK OF STUDY}

The theoretical framework of the study is the genre-based approach, focusing on the classification of text-types for the purpose of introducing various genres to students (Derewianka, 1991) and for 
developing a text-based syllabus design (Feez, 1998). As this paper is on argument texts, attention will be on this genre. According to Derewianka (1991), argument and discussion belong to a "genre group called 'Exposition', concerned with the analysis, interpretation and evaluation of the world around us" (p. 75). Discussion texts are different from argument texts in that there is a balanced presentation of for- and against- arguments without any necessary endorsement of a position (Jenkins \& Pico, 2006) but in argument texts, only one aspect of the issue is supported although opposing views may be mentioned for refuting. Examples of argument texts are newspaper editorials (Ansary \& Babaii, 2009) and research articles (Teufel \& Moens, 2000), inclusive of procedural texts (Aouladomar, F., \& Saint-Dizier, P., n.d.; Fontan \& Saint-Dizier, n.d.). Argument texts begin with the stance (thesis statement), followed by arguments for and against the issue, and end with a restatement of the stance (Derewianka, 1991). Discussion texts require a statement of the issue, arguments for and against and assessment of the issue (Feez, 1998). To support the arguments, elaboration of the main ideas, facts and anecdotes are used to convince the readers with the aid of language features such as modal verbs, personal pronouns, emotive words and connectors. The difference in the text structure arises from the purpose of argument which is to persuade the audience to take up a particular viewpoint and the purpose of discussion which is to consider the issue from various perspectives.

Argument and discussion texts are characterised by the use of language features such as generalised participants, technical terms related to the issue, a variety of verb types, mainly timeless present tense, frequent use of passives, nominalisations, connectives and emotive words (see Derewianka, 1991; Feez, 1998). Wilson's (2005) analysis of the Kolhapur Indian English Corpus showed that may and should, along with can and ought, are features of argumentative/expository text-types which included Learned and Scientific writing, Religion, Skills and Hobbies, and Press Editorials in his study. Wilson's findings concurred with Nakamura's (1993) comparison of modals in the Brown and British Lancester/OsloBergen (LOB) corpora. However, for the passive voice, Sigel (2009) did not concur with Derewianka on the need for frequent use of passives in argument texts. Sigel argues that the passive voice "makes for imprecise arguments" and the active voice allows the reader to know precisely what is occurring (p. 479). The importance of nominalising actions into things to make the argument sound 
more objective and to structure the text is stressed by Derewianka. Nominalisation is "a technique adult writers use to pack more meanings into the clause as there can only be one verb but several nouns in a clause" (see Derewianka, 1991, p. 64).

\section{METHOD OF STUDY}

The argument texts were written by undergraduates from Universiti Malaysia Sarawak enrolled in a Level 2 foundation English course designed for those with Malaysian University English Test (MUET) bands 1 to 3 . These undergraduates had passed the Level 1 foundation course which emphasised the use of oral communication skills in social situations frequently encountered by university students such as interacting with lecturers, talking about schedules, and describing places and persons (see Ting, Kamil, Ho, Tuah \& Campbell, 2009). In the Level 2 foundation course, the emphasis was on developing the undergraduates' reading and writing skills using social issues and situations as the content. The undergraduates were taught five text-types in the course using the genre-based approach: recount, description, information report, explanation and argument (see Mustafa, Mahadhir \& Ting, 2009). Discussion was not included in the course because this was found to be a relatively easier text-type than argument, explanation, information report and instruction (Ting $\&$ Tee, 2008b). The study also revealed that argument texts needed attention because the stance was not clearly stated at the beginning and not clinched towards the end of the text.

The module on the argument text-type in the Level 2 foundation course was modelled upon the teaching-learning cycle for the genrebased approach (Derewianka, 1991; Feez, 1998). The module began with the building of background knowledge on animal abuse from the undergraduates' experiences with pets and mistreatment of other domestic animals. The next stage in the teaching-learning cycle was the deconstruction of the model text. The undergraduates were asked to read debate texts on the effectiveness of legislation and education in the prevention of animal abuse for main ideas in order to draw their attention to the organisational structure of arguments. Following the comprehension activity, selected language features relevant for achieving the persuasive purpose of the debate texts were pointed out. For example, emotive words, analogies, modal verbs and reader engagement strategies such as rhetorical questions and personal 
pronouns. Then the undergraduates were given grammar exercises on these selected language features using other argument texts in the form of Letters to the Editor and blog postings. To scaffold the process of writing argument texts, a joint construction of a Letter to the Editor to call for public support for stricter legislation against animal abuse was carried out. Finally, the undergraduates were asked to individually write a Letter to the Editor to call for public action to prevent animal abuse. This was the argument text analysed in this study.

In this study, high and low English proficiency groups are defined as students with scores in the top and bottom $20 \%$ of the total marks for an argument text. The argument text was marked out of 25 marks as follows:

Title (1 mark)

Content:

Thesis (1 mark)

3 arguments (2 marks each)

Restate thesis (2 marks)

Persuasive language:

Involve reader (3 marks)

Modal verbs (3 marks)

Language accuracy:

Subject-verb agreement and tenses (4 marks)

Vocabulary (2 marks)

Spelling and punctuation (2 marks)

Paragraphing (1 mark)

Undergraduates with scores of 20 and above were considered as the proficient group. The less-proficient group comprised argument texts with scores of 10 and below with the exception of the handful who misinterpreted the question. On this basis, 40 texts were obtained from 158 undergraduates in six classes: 22 in the proficient group and 18 in the less-proficient group. A majority of the undergraduates were in the middle category. The unequal number in the proficient and less-proficient groups was due to the availability of scripts with the predetermined scores. To ensure that the results are not skewed by the use of frequencies, the numbers were converted to percentages. 
The analysis of the argument texts was based on Derewianka's (1991) framework of text-types derived from the functional approach to language in the classroom, which emphasises the making of meaning at the text level. According to Derewianka, the text structure of an argument comprises:

- a statement of position or thesis statement, often accompanied by some background information about the issue in question; arguments supported by evidence and examples; and summing up of the position.

The students' writing for these different parts of the argument text was rated as clearly stated, stated but not clear, and not stated.

The language features Derewianka lists as important for effective arguments are generalised participants, technical terms relating to the issue, variety of verb types, mainly timeless present tense, frequent use of passives, nominalisations, connectives associated with reasoning, emotive words and modal verbs. Nominalisation happens when one word used as a verb or adjective in the first sentence is changed into a noun in the second sentence. For example, "She called for help when she was robbed. Fortunately, her call for help was heard by a passer-by. " In our study, we selectively focused on passive voice, conditionals, modal verbs, connectors and nominalisation. A frequency count of these language features was carried out, and incorrect use was noted. For example, wrongly formulated passives include Animal must be love like human and Campaign awareness can be done. Similarly, the sentence "If they do the right way for pets, they are not pet abuser" was counted as an instance of the incorrect use of the conditional. The analysis was carried out by one rater and cross-checked for accuracy by a second rater.

\section{RESULTS AND DISCUSSION}

The results from the analysis of the structure and selected language features of argument texts show that proficiency in English influenced the effectiveness of the argument texts written by the 22 proficient (P) and 18 less-proficient (LP) students at a Malaysian university. The excerpts included for illustration have not been edited for grammaticality to preserve the authenticity of the data. 
Table 1 shows that the proficient undergraduates were better at using the structure considered effective for argument texts. The percentages in Table 1 are calculated based on the total number of proficient $(n=22)$ and less-proficient $(n=18)$ undergraduates. All the 22 proficient undergraduates wrote a clear thesis statement and a main point for Argument 1. Even for Argument 2, the main point was clearly presented by $95.45 \%$ (or 21) of the proficient undergraduates. It is only for Argument 3 that the number clearly stating the main point dropped to $72.73 \%$ (or 16). The proficient undergraduates were generally able to sum up their position towards the end $(90.91 \%$ or 20$)$.

\section{Structure of Argument}

Table 1

Structure of Argument Texts Written by Proficient and Less Proficient Undergraduates

\begin{tabular}{|c|c|c|c|c|c|c|}
\hline \multirow{2}{*}{$\begin{array}{l}\text { Stages of } \\
\text { Argument }\end{array}$} & \multicolumn{2}{|c|}{ Clearly stated } & \multicolumn{2}{|c|}{$\begin{array}{l}\text { Stated but not } \\
\text { clear }\end{array}$} & \multicolumn{2}{|c|}{ None } \\
\hline & $\mathrm{P}$ & LP & $\mathrm{P}$ & LP & $\mathrm{P}$ & LP \\
\hline Stance & $\begin{array}{c}22 \\
(100 \%)\end{array}$ & $\begin{array}{c}5 \\
(27.78 \%)\end{array}$ & $\begin{array}{c}0 \\
(0 \%)\end{array}$ & $\begin{array}{c}4 \\
(2.22 \%)\end{array}$ & $\begin{array}{c}0 \\
(0 \%)\end{array}$ & $\begin{array}{c}9 \\
(50.00 \%)\end{array}$ \\
\hline Argument 1 & $\begin{array}{c}22 \\
(100 \%)\end{array}$ & $\begin{array}{c}12 \\
(66.67 \%)\end{array}$ & $\begin{array}{c}0 \\
(0 \%)\end{array}$ & $\begin{array}{c}6 \\
(3.33 \%)\end{array}$ & $\begin{array}{c}0 \\
(0 \%)\end{array}$ & $\begin{array}{c}0 \\
(0 \%)\end{array}$ \\
\hline Argument 2 & $\begin{array}{c}21 \\
(95.45 \%)\end{array}$ & $\begin{array}{c}5 \\
(27.78 \%)\end{array}$ & $\begin{array}{c}0 \\
(0 \%)\end{array}$ & $\begin{array}{c}6 \\
(3.33 \%)\end{array}$ & $\begin{array}{c}1 \\
(4.55 \%)\end{array}$ & $\begin{array}{c}7 \\
(38.89 \%)\end{array}$ \\
\hline Argument 3 & $\begin{array}{c}16 \\
(72.73 \%)\end{array}$ & $\begin{array}{c}1 \\
(5.56 \%)\end{array}$ & $\begin{array}{c}1 \\
(4.55 \%)\end{array}$ & $\begin{array}{c}2 \\
(1.11 \%)\end{array}$ & $\begin{array}{c}5 \\
(22.73 \%)\end{array}$ & $\begin{array}{c}15 \\
(83.33 \%)\end{array}$ \\
\hline Restate Stance & $\begin{array}{c}20 \\
(90.91 \%)\end{array}$ & $\begin{array}{c}2 \\
(11.11 \%)\end{array}$ & $\begin{array}{c}2 \\
(9.09 \%)\end{array}$ & $\begin{array}{c}5 \\
(27.78 \%)\end{array}$ & $\begin{array}{c}0 \\
(0 \%)\end{array}$ & $\begin{array}{c}11 \\
(61.11 \%)\end{array}$ \\
\hline
\end{tabular}

In contrast, the less-proficient undergraduates deviated from the structure of argument texts. Only $27.78 \%$ (or 5) out of 18 lessproficient undergraduates clearly stated their stance at the beginning 
of the argument and only $11.11 \%$ (or 2) clearly restated their stance at the end of the text. The stance and restatement of stance were absent in $50 \%$ (or 9) and $61.11 \%$ (or 11) of the less-proficient undergraduates' argument texts respectively. The remaining lessproficient undergraduates' attempted to state their stance but it was not clear. As for the arguments, only $66.67 \%$ (or 12) less-proficient undergraduates could clearly present the main idea in Argument 1 and fewer wrote effective Argument 2 (27.78\% or 5) and Argument $3(5.56 \%$ or 1$)$. The results showed that the structure of the argument texts was difficult for the less-proficient undergraduates to learn, unlike the proficient group who was able to structure their argument texts effectively. The results concur with Jenkins and Pico (2006) on the ability of better writers to produce well organised essays and the inability of weaker students to write good introductions and conclusions for argument texts. Considering that compliance with conventions of the genre is a more serious problem than surface language errors in students' writing (Sidaway, 2006), the results suggest that academic reading and writing courses targeted at lessproficient learners need to emphasize the teaching of the macroorganisational structure of various types of academic texts. Tasks such as identifying and writing the purpose of the text and topic sentences may help in raising awareness on the value of a good structure.

\section{LANGUAGE FEATURES OF ARGUMENT TEXTS}

The selected language features analysed are connectors, modal verbs, passive voice, conditionals and nominalisation. In Tables 2-5, the frequencies are converted to percentages to show the proportion of language features used by the proficient and the less-proficient group.

Connectors. Table 2 shows that the proficient students used more connectors (137 or $67.49 \%$ of 203 ) than the less-proficient learners (66 or $32.51 \%$ of 203). More connectors were used for giving reason (57) and showing effect (64) than for contrasting ideas (30) or adding points (29). In the category of connectors for giving reason, because is the most frequently used connector with little use of other alternatives such as in doing so, that is why, as a result and due to. The sentences containing because were grammatically correct but of lower syntactical complexity as shown in the excerpts: 
Table 2

Frequency of Connectors in Argument Text Written by Proficient and Less Proficient Undergraduates

\begin{tabular}{|c|c|c|c|c|}
\hline Connectors & & $\mathrm{P}$ & LP & Total \\
\hline \multirow{5}{*}{$\begin{array}{l}\text { To give } \\
(n=57)\end{array}$} & Because & $26(53.06 \%)$ & $23(46.94 \%)$ & 49 \\
\hline & By/In doing so & $2(100 \%)$ & $0(0 \%)$ & 2 \\
\hline & That is why & $1(100 \%)$ & $0(0 \%)$ & 1 \\
\hline & As a Result & $0(0 \%)$ & $1(100 \%)$ & 1 \\
\hline & Due to & $3(75 \%)$ & $1(25 \%)$ & 4 \\
\hline \multirow{4}{*}{$\begin{array}{l}\text { To show effect } \\
(n=64)\end{array}$} & So & $23(71.88 \%)$ & $9(28.13 \%)$ & 32 \\
\hline & Therefore & $17(85 \%)$ & $3(16.67 \%)$ & 20 \\
\hline & Hence & $10(100 \%)$ & $0(0 \%)$ & 10 \\
\hline & Thus & $2(100 \%)$ & $0(0 \%)$ & 2 \\
\hline \multirow{4}{*}{$\begin{array}{l}\text { To show contrast } \\
(\mathrm{n}=30)\end{array}$} & But & $10(52.63 \%)$ & $9(47.47 \%)$ & 19 \\
\hline & However & $5(83.33 \%)$ & $1(16.67 \%)$ & 6 \\
\hline & Although...but & $3(75 \%)$ & $1(25 \%)$ & 4 \\
\hline & Even though...but & $1(100 \%)$ & $0(0 \%)$ & 1 \\
\hline To show outcome & So that/that & $8(80 \%)$ & $2(20 \%)$ & 10 \\
\hline$(n=14)$ & In order & $3(75 \%)$ & $1(25 \%)$ & 4 \\
\hline \multirow{3}{*}{ To add ideas } & Besides & $10(52.63 \%)$ & $9(47.37 \%)$ & 19 \\
\hline & In addition & $5(100 \%)$ & $0(0 \%)$ & 5 \\
\hline & Furthermore & $4(80 \%)$ & $1(20 \%)$ & 5 \\
\hline To show sequence & Then & $4(50 \%)$ & $4(50 \%)$ & 8 \\
\hline \multirow[t]{2}{*}{$(n=9)$} & After that & $0(0 \%)$ & $1(100 \%)$ & 1 \\
\hline & Sub-total & $137(67.49 \%)$ & $66(32.51 \%)$ & 203 \\
\hline
\end{tabular}

This is because not all the Malaysian love to watch television or spend their time by searching the internet. (P11)

I support my idea because individuals cannot prevent animal abuse. At the same time, it's because people nowadays are too busy with the career. (LP6) 
The use of because also appeared to be spoken language rather than written academic language. Similarly, for connectors to show effect, the undergraduates' preference for so (32 instances) leans towards colloquial usage:

The young children who will spend more the time with their pets compare with parents. So, most of the time who can take care of the pets is the children. (P1)

My second suggestion is the person when do animal abuse must pay sue. So when them fine guilty and them must pay the sue this is can realise because not more people can pay the sue....This is because people scare when goverment do act about animal protection. So them cant do the animal abuse. (LP17)

In the place of the connector so, 20 undergraduates used therefore which is reflective of written academic language. To show contrast, but is the most commonly used (19 instances) and to show additional points to support the argument besides is preferred (19 instances). Table 2 shows that other connectors with the same function were not used much by both groups of undergraduates. In general, the undergraduates with better proficiency in English used more connectors to provide transitions between ideas. The findings of the present study support Lee's (2003) findings on the lack in variety of connectors used in non-native speaker's texts. On the basis of Lee's findings, the writing of argument texts by the proficient group was more likely to meet the expectations of native English speakers.

Modal verbs. In argument texts, modal verbs are useful for expressing the writer's attitude towards the non-factual and nontemporal elements of the situation under consideration. Unlike connectors in which two-thirds were produced by proficient undergraduates, the frequency of modal verb usage in the argument texts written by the proficient and less-proficient groups was similar (300 or $55.15 \%$ and 244 or $44.85 \%$ respectively). The arguments texts contained an overuse of can (196 instances) to modalise the propositions put forward.

Another ways through campaign also, we can make public talk in the school and any public hall. Through public talk, that person can telling the public how to save our pet and don't be the pet abuser...In addition, we can involve Malaysian artist to attract people. (P13) 
Table 3

Frequency of Modal Verbs in Argument Text written by proficient and less-proficient undergraduates

\begin{tabular}{lllr}
\hline Modal verb & \multicolumn{1}{c}{ P } & \multicolumn{1}{c}{ LP } & Total \\
\hline Can & $123(62.76 \%)$ & $73(37.24 \%)$ & 196 \\
Will & $81(68.07 \%)$ & $38(31.93 \%)$ & 119 \\
Should & $54(78.26 \%)$ & $15(21.74 \%)$ & 69 \\
Need & $7(13.46 \%)$ & $45(86.54 \%)$ & 52 \\
Would & $6(11.76 \%)$ & $45(88.24 \%)$ & 51 \\
Must & $11(32.35 \%)$ & $23(67.65 \%)$ & 34 \\
Could & $5(71.43 \%)$ & $2(28.57 \%)$ & 7 \\
Might & $5(83.33 \%)$ & $1(16.67 \%)$ & 6 \\
Shall & $6(100 \%)$ & $0(0 \%)$ & 6 \\
May & $2(50 \%)$ & $2(50 \%)$ & 4 \\
Total & $300(55.15 \%)$ & $244(44.85 \%)$ & 544 \\
\hline
\end{tabular}

In this excerpt, P13 presents the possibility of a change from problem to solution. A larger proportion of the modal verb can was used to show definite possibility by the undergraduates with better proficiency in English (62.76\% or 119) than the less-proficient group (37.24\% or 73 ). Similarly, the modal verb will was mainly used by the proficient undergraduates $(67.52 \%$ of 117$)$ whereas the less-proficient group preferred the past tense would (45 or $88.24 \%$ of 51). Some instances of will were incorrect use of the future tense for verbs which should have been written in the present tense. The analysis revealed that the less-proficient students were inclined towards conveying strong meanings of necessity through the use of must (23 or $67.65 \%$ of 34 ) and need (45 or $86.54 \%$ of 52), unlike the proficient group who preferred should (54 or $78.26 \%$ of 69 ):

Besides that, Legislation should be as a preventive measure to curb the issue only by using legislation that the society would be more aware of pet abuse especially to the young age. They are must knowing about educate legislation.... (LP5)

In comparison, modal verbs signalling the existence of remote possibility (could) and open possibility (may, might) are less frequent in the undergraduates' argument texts. The results indicate 
that the undergraduates are uncertain of the denotative meanings of modal verbs, and point to a need for training in the effective use of hedging and boosting techniques in the context of writing argument texts (see Guinda, 2003).

Table 4

Frequency of Passive Voice in Argument Text Written by Proficient and Less-Proficient Undergraduates

\begin{tabular}{lccc}
\hline Passive voice & \multicolumn{1}{c}{ P } & LP & Total \\
\cline { 3 - 4 } Correct usage & $62(78.48 \%)$ & $17(21.52 \%)$ & 79 \\
Incorrect usage & $5(71.43 \%)$ & $2(28.57 \%)$ & 7 \\
\hline Total & $67(77.91 \%)$ & $19(22.09 \%)$ & 86 \\
\hline
\end{tabular}

Passive voice. In the 40 argument texts analysed, 86 passive sentences were found, of which $77.91 \%$ (or 62) were produced by the proficient group. A majority of the passive sentences were grammatically correct, with only 7 incorrect usages arising from the omission of the auxiliary verb (5 sentences) and using the root form of the verb instead of using the past participle (e.g. will inject instead of will be injected). The difficulty that the undergraduates have with the passive voice is similar to that found by Hinkel (2004). In the present study, the use of the passive is relatively low considering the usefulness of the passive voice to focus attention on the object of an action rather than the party involved in order to provide an objective tone. Based on an earlier study by Hinkel (1997), the infrequent use of the passive voice could be a non-native speaker attribute.

Conditionals. Table 5 shows that there is little difference between the two groups in the total number of conditionals used (17 each) and in the number of correct usage (16 by the proficient; 14 by the less proficient). Examples of incorrect usage indicate the severity of the grammatical problem in sentence construction:

For example if animal abuse issue can announcement $^{\wedge \text { be }}$ announced by society...(LP1)

...If the writer ${ }^{\wedge}$ were willing to write about how to properly care for his or her pets, I am sure...(P11) 
Table 5

Frequency of Conditionals in Argument Text Written by Proficient and Less-Proficient Undergraduates

\begin{tabular}{lccc}
\hline Conditionals & \multicolumn{1}{c}{$\mathrm{P}$} & $\mathrm{LP}$ & Total \\
\hline Correct usage & $16(53.33 \%)$ & $14(46.67 \%)$ & 30 \\
Incorrect usage & $1(25 \%)$ & $3(75 \%)$ & 4 \\
\hline Total & $17(50 \%)$ & $17(50 \%)$ & 34 \\
\hline
\end{tabular}

In the context of an argument text, the low frequency of conditionals indicates that the undergraduates were not adept at using the concessive construction to establish a speculative context to put forward a hypothesised situation. In instances where facts are not available for substantiating the argument, hypothetical situations can be used to the writer's advantage to make convincing arguments. The results point to the need to teach the use of conditionals in argument texts.

Nominalisation. In argumentative writing, nominalisation is essential to move the argument forward. The distancing and objective sense of a nominalised verb makes it ideal for formal situations such as argumentative texts or business writing. Only one instance of nominalisation was found in the 40 texts analysed, ". ...one of the ways to stop pet abuse is by educating the public. Education plays a very vital role in our daily life" (P10). Nominalisation was not emphasised in the course, and it is also probable that even the proficient students did not possess the competency which allowed them to change a verb into a noun.

To sum up, the undergraduates who had a higher level of English proficiency used more connectors, modal verbs and passive voice in writing the argument texts than their less-proficient counterparts. Although the quantity was satisfactory for the proficient group, the persuasiveness of the argument texts was compromised by the lack of variety and inappropriateness in the usage. The results indicate that the undergraduates were conscious of the need to use connectors, modal verbs and passive voice in writing the argument text but many were unable to maximise the potential of these 
language features to construct effective arguments. On the basis of these findings, academic writing instruction at university level requires more than the explanation of the forms and functions of connectors, modal verbs and the passive voice but showing students how varying the use changes the nuances of meaning at the sentence and paragraph levels. The study also revealed that conditionals and nominalisations are language features requiring pedagogical attention, even for the proficient undergraduates as they were hardly used in the argument texts.

\section{CONCLUSION}

The study on the writing of argument texts showed that undergraduates who were proficient in English wrote more persuasive texts than the less-proficient undergraduates'. The proficient group was able to organise their ideas following the structure considered effective for argument texts but the less-proficient lacked ability to state the stance at the beginning and restate the stance at the end of the text. To make their arguments persuasive, the proficient undergraduates were better at using connectors to signal transition in ideas, modal verbs to convey meanings of possibility and necessity and passive voice to provide an objective tone where necessary. However, both groups were unable to capitalise on the use of conditionals and nominalisations to push their arguments forward, suggesting that these language features need more attention when teaching undergraduates how to write persuasive texts. However, for other language features such as connectors, modal verbs and passive voice, development of materials for academic reading and writing courses needs to take account of the students' proficiency level and the teaching of these language features in context. The findings have highlighted difficulty areas which need emphasis so that valuable course time may be allocated for teaching language features which are difficult to master, and for developing variety in using language features which are easy to master. Further studies using a wider corpus covering other written and spoken argument texttypes encountered by university students would contribute towards a better understanding of undergraduates' problems in adjusting to academic language and provide empirical evidence for more targeted instruction in academic writing. 


\section{REFERENCES}

Ansary, H., \& Babaii, E. (2009). A cross-cultural analysis of English newspaper editorials: A systemic-functional view of text for contrastive rhetoric research. RELC Journal, 40, 211. Retrieved from http://rel.sagepub.com/cgi/content/abstract

Aouladomar, F., \& Saint-Dizier, P. (n.d.). Towards generating procedural texts: An exploration of their rhetorical and argumentative structure. Retrieved from http://www.irit. $\mathrm{fr} /$ Patrick.Saint-Dizier/ publi_fichier/EWNLG05.pdf

Biber, D. (2006). University language: A corpus-based study of spoken and written registers. Amsterdam: John Benjamins Publishing Company.

Cullip, P. F., \& Carol, D. (2002). Tailoring an EAP course to disciplinary needs: The UNIMAS effort. The English Teacher, XXVIII [Electronic version]. Retrieved from http:// www.melta.org.my/ET/2002/wp05.htm

Degand, L., \& Sanders, T. (2002). The impact of relational markers on expository text comprehension in L1 and L2. Reading and Writing: An Interdisciplinary Journal, 15, 739-757.

Derewianka, B. (1991). Exploring how texts work. Newtown, Australia: Primary English Teaching Association.

Feez, S. (1998). Text-based syllabus design. Sydney, Australia: Macquarie University.

Flowerdew, J. (2001). Attitudes of journal editors to non-native speaker contributions. TESOL Quarterly, 35(1), 121-150.

Fontan, L., \& Saint-Dizier, P. (n.d.). An analysis of the persuasive strength of arguments in procedural texts. Retrieved from http://www.aisb.org.uk/convention/aisb09/Proceedings/ PERSUASIVE/FILES/SAINT-DIZIERP.pdf

Gerot, L., \& Wignell, P. (1994). Making sense offunctional grammar. Cammeray, NSW: Antipodean Educational Enterprise.

Grabe, W., \& Kaplan, R. B. (1996). Theory \& practice of writing. London: Longman.

Guinda, C. S. (2003). Contractual role of modality as convergence strategy in technical research articles. RESLA, 16, 219-233.

Jackson, L., Meyer, W., \& Parkinson, J. (2006). A study of the writing tasks and reading assigned to undergraduate science students at a South African University. English for Specific Purposes, 25(3), 260-281.

Jenkins, H. H., \& Pico, M. L. (2006). SFL and argumentative essays in ESOL. Proceedings of $33^{\text {rd }}$ International Systemic Functional Congress, 155. 
Hinkel, E. (1997). Indirectness in L1 and L2 academic writing. Journal of Pragmatics, 27(3), 361-386.

Hinkel, E. (2004). Tense, aspect and the passive voice in L1 and L2 academic texts. Language Teaching Research, 8(1), 5-29.

Horowitz, D. M. (1986). What professors actually require: Academic tasks for the ESL classroom. TESOL Quarterly, 20(3), 445462.

Johns, A. M. (1997). Text, role, and context: Developing academic literacies. Cambridge: Cambridge University Press.

Lee, M. Y. P. (2003). Structure and cohesion of English narratives by Nordic and Chinese students. Inordlyd, 31(2), 290-302.

Millis, K. K., Graesser, A. C., \& Haberlandt, K. (1993). The impact of connectives on the memory for expository texts. Applied Cognitive Psychology, 7, 317-339.

Mustafa, R., Mahadhir, M., \& Ting, S. H. (2009). English for social and academic purposes. Petaling Jaya, Malaysia: McGrawHill.

Nakamura, J. (1993). Quantitative comparison of modals in the Brown and LOB corpora. International Computer Archive of Modern and Medieval English (ICAME) Journal, 12, 15-26.

Sidaway, R. (2006). The genre-based approach to teaching writing. English (Spring Volume), 24-27.

Sigel, T. (2009). How passive voice weakens your scholarly argument. Journal of Management Development, 28(5), 478480.

Teufel, S., \& Moens, M. (2005). What's yours and what's mine: Determining intellectual attribution in scientific text. Retrieved from http://delivery.acm.org/ 10.1145/1120000/1117796/p9teufel.pdf

Thompson, P. (1997). Introducing functional grammar. London: Arnold.

Ting, S. H., Kamil, S. M., Ho, A. P., Tuah, A. S. B. M., \& Campbell, Y. M. (2009). English for social purposes (2nd ed.). Petaling Jaya, Malaysia: McGraw-Hill.

Ting, S. H., \& Law, L. (2008). Genre-based approach to teaching English for Academic Purposes: Changes in undergraduates' academic writing. Proceedings of International Conference on Teaching and Learning, Petaling Jaya, Malaysia.

Ting, S. H., \& Tee, P. F. (2008a). English for Academic Purposes and quality of undergraduates' academic writing. Proceedings of 2nd National Conference on "Skills and Competencies in Education: Emerging issues, trends, challenges and directions" (NCSCE 2008). Pulau Pinang, Malaysia. 
Ting, S. H., \& Tee, P. F. (2008b). TESL undergraduates' ability to handle academic text-types at Universiti Malaysia Sarawak. Asiatic Journal of Languages and Literatures, 2(2), 85-100.

Ting, S. H., \& Tee, P. F. (2009). Organisational and grammatical features of explanations written by Biology undergraduates. Proceedings of $4^{\text {th }}$ International Conference on English Language Teaching (ELT-CON). Pulau Pinang, Malaysia.

Wilson, A. (2005). Modal verbs in written Indian English: A quantitative and comparative analysis of the Kolhapur corpus using correspondence analysis. International Computer Archive of Modern and Medieval English (ICAME) Journal, 29, 151-170.

Zadeh, E. A. (2006). The role of textual signals in L2 text comprehension, ESP Malaysia, 12, 1-18.

Zhu, W. (2004). Writing in business courses: An analysis of assignment types, their characteristics, and required skills. English for Specific Purposes, 23, 111-35. 